\title{
Friction underwear for ease of pulling down in elderly patients with overactive bladder: A prospective randomized control trial
}

\author{
Jae Hyung You ${ }^{1, *}$, Yu Seob Shin ${ }^{1, *}$, Myoung-Hwan Ko ${ }^{2}$, Eun Jin Jeon ${ }^{3}$, Heecheon You ${ }^{3}$, Jong Kwan Park ${ }^{1}$ \\ Departments of 'Urology and 'Physical Medicine and Rehabilitation, Chonbuk National University Medical School, Research Institute of Clinical Medicine of Chonbuk \\ National University-Biomedical Research Institute and Clinical Trial Center of Medical Device of Chonbuk National University Hospital, Jeonju, ${ }^{3}$ Department of Industrial \\ and Management Engineering, Pohang University of Science and Technology, Pohang, Korea
}

Purpose: Friction underwear was developed by adding small silicon dots in front of the underwear to decrease the time for pulling down underwear in elderly patients with urge incontinence. We studied about the effects of the friction underwear for elderly overactive bladder (OAB) patients.

Materials and Methods: Male patients over 60 years of age diagnosed with OAB were prospectively enrolled and randomized to either the friction underwear first group (measuring for the time taken to pull down the friction underwear first and the nonfriction underwear second) or the friction underwear later group (non-friction underwear first and the friction underwear second). An investigator measured the time to pulling down the underwear. And we measured the coefficient of friction of underwear.

Results: A total of 56 male patients were randomly divided into two groups using a random number table envelope method. There were no significant differences in demographics and clinical characteristics between the two groups. Of the total 56 patients, the time taken to pull down underwear for the friction underwear $(3.79 \pm 0.15$ seconds) was found significantly shorter than that for the non-friction underwear $(4.10 \pm 0.17$ seconds) $(p=0.03)$. The static and dynamic coefficients of friction of the friction were 4.21 and 2.88 , respectively, while those of the non-friction underwear were 0.64 and 0.45 , respectively.

Conclusions: Our study demonstrates that friction underwear significantly shortened the time to pull down underwear. This functional underwear may be effective in preventing the underwear from getting wet in patients who suffer from urge incontinence.

Keywords: Clothing; Urinary bladder, overactive; Urinary incontinence, urge

This is an Open Access article distributed under the terms of the Creative Commons Attribution Non-Commercial License (http://creativecommons.org/licenses/by-nc/4.0) which permits unrestricted non-commercial use, distribution, and reproduction in any medium, provided the original work is properly cited.

\section{INTRODUCTION}

Overactive bladder $(\mathrm{OAB})$ is characterized by urinary urgency, with or without urge incontinence, and usually accompanied by frequency and nocturia if there is no proven infection or other obvious pathology [1]. Urgency, an

Received: 8 January, 2019 - Accepted: 3 March, 2019

Corresponding Author: Jong Kwan Park

Department of Urology, Chonbuk National University Medical School, Research Institute of Clinical Medicine of Chonbuk National University-Biomedical Research Institute and Clinical Trial Center of Medical Device of Chonbuk National University Hospital, 20 Geonji-ro, Deokjin-gu, Jeonju 54907, Korea TEL: +82-63-250-1510, FAX: +82-63-250-1564, E-mail: rain@chonbuk.ac.kr

ORCID: https://orcid.org/0000-0001-9682-2081

*These authors contributed equally to this study and should be considered co-first authors. 
abnormal sensation defined as the complaint of a sudden compelling desire to void that is difficult to defer, is one of the $\mathrm{OAB}$ symptoms with the greatest impact on the quality of life (QOL) of patients [2]. Moreover, storage symptoms have significantly large impacts on the QOL of patients compared with lower urinary tract symptoms (LUTS) [3]. The prevalence of $\mathrm{OAB}$ increases with age and there is a progression from an "OAB dry" to urge urinary incontinence over time in the general population [4].

Hand function decreases with age in both men and women, especially after the age of 65 years [5]. Moreover, dry skin is a common skin condition in the elderly [6]. Based on our experience, many $\mathrm{OAB}$ patients primarily feel urgency and the occurrence of incontinence in an instant during the process of pulling down their underwear. We assumed that elderly OAB patients could not pull down their underwear easily due to decreased hand function and dry skin and suffer from a severe degree of urge incontinence.

Based on these insights, we invented friction underwear by adding small silicon dots in front of the underwear (patent registration number in South Korea: 10-1378146) to decrease the time to pull down underwear in elderly $\mathrm{OAB}$ patients suffering from urgency or urge incontinence (Fig. 1). We evaluated the time difference in pulling down underwear for friction underwear and non-friction underwear in elderly $\mathrm{OAB}$ patients.

\section{MATERIALS AND METHODS}

The present study was approved by the Institutional Review Board (CUH 2014-10-022-002) at the Chonbuk National University Hospital and was performed between December 2015 to February 2016 within framework of a prospective randomized controlled trial (1:1). Patients were over 60 years of age diagnosed with $\mathrm{OAB}$ were recruited to the present study. Patients were allocated into two groups using blinded randomization blocks in order to eliminate the learning effect. The friction underwear first group was measured for the time taken to pull down the friction underwear first and the non-friction underwear second, while the friction underwear later group was measured for the time taken to pull down the non-friction underwear first and the friction underwear second (Fig. 2). Informed consent was obtaind from all the patients prior to enrollment. This work was performed by following the CONSORT criteria. All patients provided written informed consent before screening. The primary outcome was to evaluate efficacy of friction underwear to decrease the time for pulling down underwear. The secondary outcome was to evaluate industrial coefficient of friction (COF) of friction underwear in the patients with LUTS. The inclusion criterion of the present study is a performance status less than two according to the Eastern Cooperative Oncology Group (ECOG) scale. The exclusion criteria of the present study included a body mass index (BMI) greater than $40 \mathrm{~kg} / \mathrm{m}^{2}$, evidence of a clinically significant orthopedic or neurologic disease, and conditions which could interfere with the ability to provide informed consent, comply with study instructions, place the subject at an increased risk, and might confound the interpretation of the study results.

We ordered 60 pieces of cotton underwear from a clothing manufacturer. Half of the underwear pieces went through application of silicon dots in the front. A single investigator measured the time to pull down the zipper of the pants and the belt of the underwear until completely exposing the penis outside by the dominant hand. The duration of pulling down the underwear was timed with a stopwatch and defined as the time taken from unzipping the pants and pulling down the band of underwear until the penis was exposed. We entrusted the Korea Apparel Testing and Research Institute to measure the COF of underwear.

The product used in this clinical trial is the friction underwear to prevent getting wet underwear by urge incontinence. Because there was no previous research on the functional underwear developed by myself, this study was proceeded with the pilot study. Independent sample t-test was used to compare the difference of mean values of continuous variables in two groups. In order to confirm
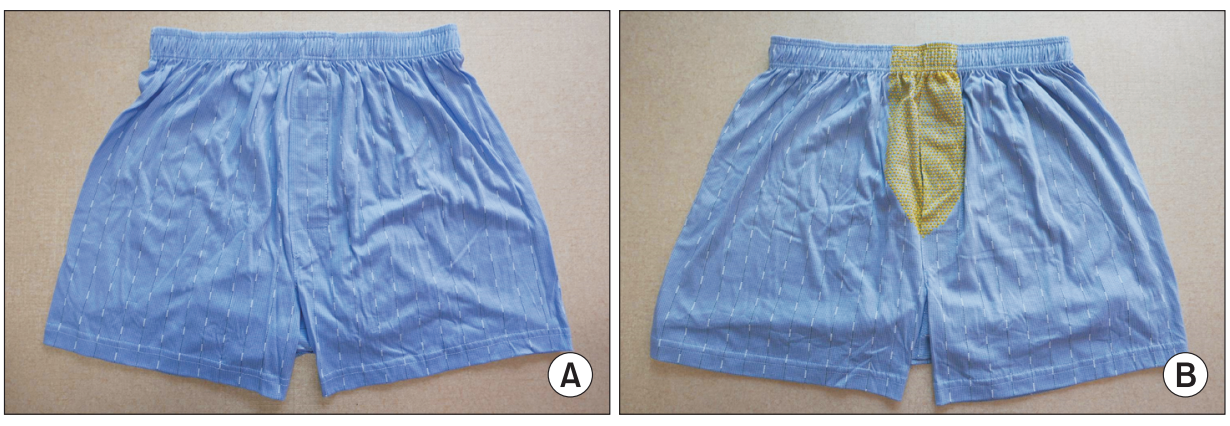

Fig. 1. The underwear without $(A)$ or with (B) multiple small silicone balls applied to the restrictive area. 


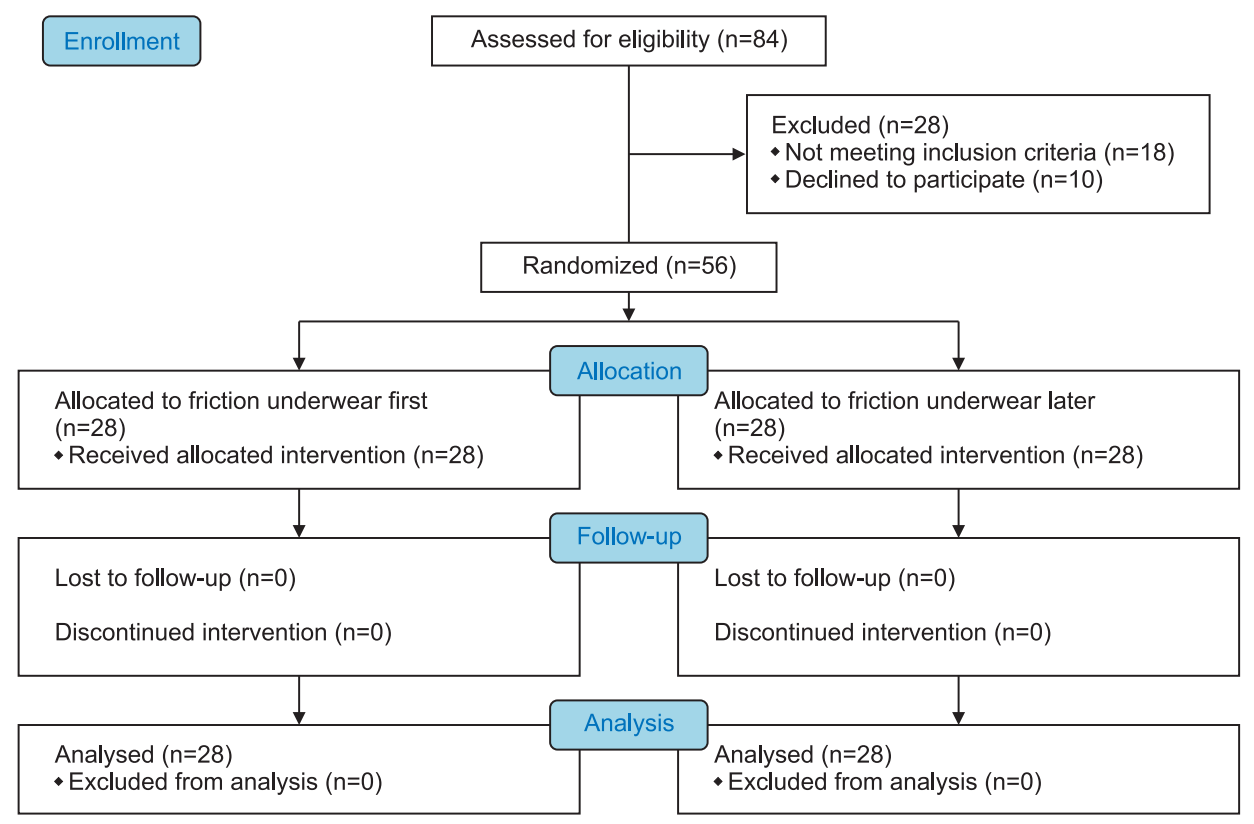

Fig. 2. CONSORT flow diagram.

Table 1. Demographics and clinical characteristics

\begin{tabular}{|c|c|c|c|c|}
\hline Parameters & $\begin{array}{c}\text { Total patients } \\
(n=56)\end{array}$ & $\begin{array}{l}\text { Friction underwear } \\
\text { first }(n=28)\end{array}$ & $\begin{array}{l}\text { Friction underwear } \\
\text { later }(n=28)\end{array}$ & p-value \\
\hline Age $(y)$ & $66.77 \pm 4.35$ & $66.86 \pm 4.41$ & $66.68 \pm 4.37$ & 0.89 \\
\hline Male & $56(100.0)$ & $28(100.0)$ & $28(100.0)$ & \\
\hline Eastern Cooperative Oncology Group performance status scale & $0.12 \pm 0.33$ & $0.11 \pm 0.31$ & $0.14 \pm 0.36$ & 0.71 \\
\hline Body mass index $\left(\mathrm{kg} / \mathrm{m}^{2}\right)$ & $25.54 \pm 3.44$ & $25.79 \pm 3.53$ & $25.29 \pm 3.39$ & 0.12 \\
\hline Overactive Bladder Symptom Score & $5.96 \pm 1.97$ & $5.89 \pm 1.93$ & $6.04 \pm 2.02$ & 0.81 \\
\hline International Prostate Symptom Score & $15.27 \pm 6.14$ & $14.68 \pm 5.81$ & $15.86 \pm 6.51$ & 0.53 \\
\hline Prostate volume $(\mathrm{mL})$ & $32.89 \pm 13.54$ & $30.43 \pm 11.31$ & $35.29 \pm 15.27$ & 0.18 \\
\hline Prostate specific antigen $(\mathrm{ng} / \mathrm{mL})$ & $1.83 \pm 2.08$ & $1.57 \pm 1.98$ & $2.07 \pm 2.19$ & 0.35 \\
\hline Maximum flow rate $(\mathrm{mL} / \mathrm{sec})$ & $15.26 \pm 6.08$ & $16.46 \pm 6.70$ & $14.06 \pm 5.25$ & 0.14 \\
\hline Hypertension & $15(26.8)$ & $7(25.0)$ & $8(28.6)$ & 0.71 \\
\hline Diabetes & $7(12.5)$ & $4(14.3)$ & $3(10.7)$ & 0.79 \\
\hline
\end{tabular}

Values are presented as mean \pm standard deviation or number (\%).

the effectiveness of the friction underwear, the times to pull down the friction underwear and the non-friction underwear were analyzed at $\alpha=0.5$ by the pair of the mean difference within paired measurements, using IBM SPSS ver. 22.0 (IBM Co., Armonk, NY, USA). A priori power analysis using $G^{*}$ Power version 3.1.9.2 identified that at least 27 of sample size is needed to detect a mean difference of 0.5 seconds with a standard deviation of 1 second for the significance level of 0.05 and a statistical power of 0.8 using a one-sided t-test to paired time measurements of pulling down friction underwear and non-friction underwear [7].

\section{RESULTS}

A total of 56 male patients were randomly divided into two groups using the random number table envelope method. The order of trial between friction underwear and non-friction underwear was counterbalanced among the participants. No subjects were excluded or dropped out from the clinical trial. Patient data are summarized in Table 1. There were no significant differences between the two groups in terms of mean patient age, male/female ratio, mean ECOG performance status scale, mean BMI, OAB symptom score, International Prostate Symptom Score, prostate volume, prostate specific antigen level, maximum flow rate, hypertension, and diabetes.

Of the total 56 patients, the time taken to pull down underwear for the friction underwear (3.79 \pm 0.15 seconds) was found significantly shorter than that for the non-friction underwear (4.10 \pm 0.17 seconds; $p=0.03)$ as displayed in Fig. 3 . 


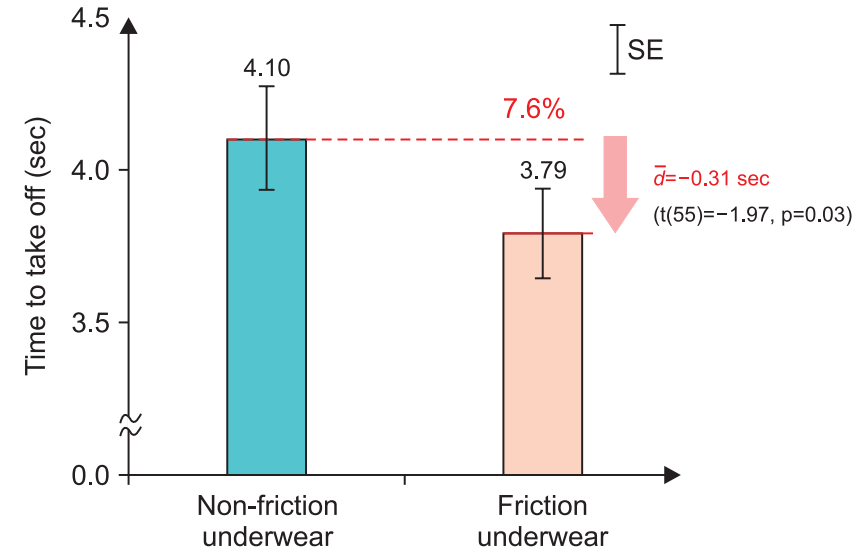

Fig. 3. Time to pull down the underwear. $\bar{d}$, difference; SE, standard error; $t$, t-test.

The Korea Apparel Testing and Research Institute measured the COFs of the friction underwear and the nonfriction underwear. The static and dynamic COFs of the friction were 4.21 and 2.88 , respectively, while those of the non-friction underwear were 0.64 and 0.45 , respectively.

\section{DISCUSSION}

Using the standardized International Continence Society definition of OAB, the European Prospective Investigation into Cancer and Nutrition study, a population-based, crosssectional telephone survey of adults aged $\geq 18$ years in four European countries and Canada, reported an overall $\mathrm{OAB}$ prevalence of $11.8 \%$ in the context of a prevalence of $64.3 \%$ for at least one of the LUTS [8]. The prevalence of benign prostatic hyperplasia and of moderate to severe LUTS increased with age [9]. Aging is clearly associated with increased LUTS, especially in OAB; the wide range of changes in the central nervous system and cellular function that is associated with increasing $\mathrm{OAB}$ with aging is likely multifactorial. Partial bladder outlet obstruction has been considered to be an etiologic factor of OAB. Based on our experience, many patients feel the greatest urgency and occurrence of getting wet by incontinence during the process of pulling down their underwear. To the best of our knowledge, no studies have been conducted to determine when patients suffer from the highest feelings of urgency in OAB patients. We believe that such research may help to improve the overall QOL of $\mathrm{OAB}$ patients.

Hand function decreases with aging in both men and women, especially after the age of 65 years. Elderly individuals commonly experience difficulties in hand functioning requiring fine precision grip and loss of hand strength which can affect the ability to perform simple daily actions. Deterioration of hand function in the elderly results from a combination of local structural changes in the related joints, muscles, tendons, bones, nerves and receptors, blood supply, skin, and fingernails and distant changes in neural control [5]. Dry skin (xerosis) is a common skin condition in older adults. Xerosis in older adults is attributed to multifactorial intrinsic changes in keratinization and lipid content, use of diuretics and similar medications, overuse of heaters or air conditioners, and dry climates [6]. The present study assumed that decreased hand function and dry skin make elderly $\mathrm{OAB}$ patients prevent from pulling down underwear with ease. In the cold season, LUTS tend to worsen [10]. In dry and cold weather, hands become drier and it will be harder to pulling down underwear as soon as possible. Based on these insights, we invented the functional friction underwear having partially attached small silicon dots to the restrictive area in the front of the underwear to decrease the time required to pull down the underwear in elderly $\mathrm{OAB}$ patients. The friction underwear provides a better friction than the non-friction underwear, as tested by the apparel research institute. Our findings indicate that the friction underwear significantly decreased the time required to pull down the underwear. New friction underwear needs to be developed using better friction materials and an improved shape to pull down more easily.

Female has a higher prevalence of $\mathrm{OAB}$ than male [11]. The National Overactive Bladder Evaluation study established the prevalence of $\mathrm{OAB}$ in more than 5,000 individuals in the United States using a validated computerassociated telephone interview In women, the prevalence of "OAB wet" rose from $2.0 \%$ in the young group (18 to 24 years) to $19.1 \%$ in the old group (65 to 74 years) [12]. With this in mind, functional friction lingerie can be effective for elderly women with $\mathrm{OAB}$.

$\mathrm{OAB}$ is progressive but can be stable for a prolonged period of time and remission can occur [13]. To the best of our knowledge, stabilization or remission factors of $\mathrm{OAB}$ have not been studied. The present study demonstrates for the first time that the friction underwear significantly shortened the time to pull down underwear. It can be further examined if friction underwear is effective for the ability to stabilize the $\mathrm{OAB}$ patients with urge incontinence.

This study had several limitations. First, the time it takes to pulling down friction underwear is shortened by about 0.3 seconds, but there is a question about whether this 0.3 seconds is clinically meaningful. In urge incontinence situation, however, this short time could be helpful to prevent the elderly $\mathrm{OAB}$ person getting wet. We hope that further study will be done on how this 0.3 seconds impacts 
to urge incontinence frequency and QOL. Second, due to small patient number, the results of this study should be interpreted cautiously. Third, a habit of the elderly person to pick up a portion to pull down underwear, such as belt area, front or lower portion, or small opening of the underwear to take out the penis for voiding, etc. Based on this study, we hope to have a large-scale study of the effectiveness of friction underwear in the future.

\section{CONCLUSIONS}

We invented friction underwear by attaching small silicon dots in the front of underwear to decrease the time required to pull down underwear in elderly $\mathrm{OAB}$ patients. It was found that the friction underwear significantly shortened the time required to pull down the underwear. The study result suggests that friction underwear can be recommended to $\mathrm{OAB}$ patients to improve their QOL by preventing the underwear from getting wet in those who suffer from urge incontinence (Video clip, Supplementary material).

\section{CONFLICTS OF INTEREST}

The authors have nothing to disclose.

\section{ACKNOWLEDGMENTS}

Authors thank the members of the medical device clinical trial center of Chonbuk National University Hospital for helpful discussions.

This study was supported by grants from the Biomedical Research Institute of Chonbuk National University Hospital, Jeonju, Korea. This research was also supported by a grant of the Korea Health Technology R\&D Project through the Korea Health Industry Development Institute (KHIDI), funded by the Ministry of Health \& Welfare, Republic of Korea (grant number: HI15C1529). And the present study was jointly supported by Fund of Biomedical Research Institute, Chonbuk National University Hospital, Basic Science Research Program through the National Research Foundation of Korea (NRF) funded by the Ministry of Education (NRF-2017R1D1A1B03036081). However, Biomedical Research Institute of Chonbuk National University Hospital, the Ministry of Health and Welfare and the Ministry of Education, Republic of Korea had no role in design or conduct of the study including collection, management, analysis, or interpretation of the data in addition to preparation, review, or approval of the manuscript.

\section{SUPPLEMENTARY MATERIAL}

Accompanying video can be found in the "Urology in Motion' section of the journal homepage (http://www. icurology.org). The supplementary video clip can also be accessed by scanning a QR code, or be available on YouTube: https:/youtu.be/BePRyt4sM6E.

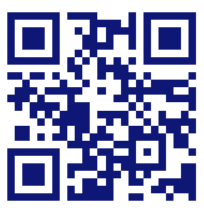

\section{REFERENCES}

1. Abrams P, Artibani W, Cardozo L, Dmochowski R, van Kerrebroeck P, Sand P; International Continence Society. Reviewing the ICS 2002 terminology report: the ongoing debate. Neurourol Urodyn 2009;28:287.

2. Milsom I, Kaplan SA, Coyne KS, Sexton CC, Kopp ZS. Effect of bothersome overactive bladder symptoms on health-related quality of life, anxiety, depression, and treatment seeking in the United States: results from EpiLUTS. Urology 2012;80:90-6.

3. Sexton CC, Coyne KS, Kopp ZS, Irwin DE, Milsom I, Aiyer LP, et al.; EpiLUTS Team. The overlap of storage, voiding and postmicturition symptoms and implications for treatment seeking in the USA, UK and Sweden: EpiLUTS. BJU Int 2009;103 Suppl 3:12-23.

4. Irwin DE, Milsom I, Chancellor MB, Kopp Z, Guan Z. Dynamic progression of overactive bladder and urinary incontinence symptoms: a systematic review. Eur Urol 2010;58:532-43.

5. Carmeli E, Patish H, Coleman R. The aging hand. J Gerontol A Biol Sci Med Sci 2003;58:146-52.

6. White-Chu EF, Reddy M. Dry skin in the elderly: complexities of a common problem. Clin Dermatol 2011;29:37-42.

7. Faul F, Erdfelder E, Lang AG, Buchner A. G*Power 3: a flexible statistical power analysis program for the social, behavioral, and biomedical sciences. Behav Res Methods 2007;39:175-91.

8. Irwin DE, Milsom I, Hunskaar S, Reilly K, Kopp Z, Herschorn $S$, et al. Population-based survey of urinary incontinence, overactive bladder, and other lower urinary tract symptoms in five countries: results of the EPIC study. Eur Urol 2006;50:1306-14.

9. Huh JS, Kim YJ, Kim SD. Prevalence of benign prostatic hyperplasia on Jeju Island: analysis from a cross-sectional community-based survey. World J Mens Health 2012;30:131-7.

10. Choi HC, Kwon JK, Lee JY, Han JH, Jung HD, Cho KS. Seasonal variation of urinary symptoms in korean men with lower 
urinary tract symptoms and benign prostatic hyperplasia. World J Mens Health 2015;33:81-7.

11. Coyne KS, Sexton CC, Bell JA, Thompson CL, Dmochowski R, Bavendam $\mathrm{T}$, et al. The prevalence of lower urinary tract symptoms (LUTS) and overactive bladder (OAB) by racial/ethnic group and age: results from OAB-POLL. Neurourol Urodyn 2013;32:230-7.
12. Stewart WF, Van Rooyen JB, Cundiff GW, Abrams P, Herzog AR, Corey R, et al. Prevalence and burden of overactive bladder in the United States. World J Urol 2003;20:327-36.

13. Heidler S, Mert C, Temml C, Madersbacher S. The natural history of the overactive bladder syndrome in females: a longterm analysis of a health screening project. Neurourol Urodyn 2011;30:1437-41. 